\title{
Characterization of Natural Dye Extracted from Wormwood and Purple Cabbage for Dye-Sensitized Solar Cells
}

\author{
Ho Chang, ${ }^{1}$ Mu-Jung Kao, ${ }^{2}$ Tien-Li Chen, ${ }^{3}$ Chih-Hao Chen, ${ }^{4,5}$ \\ Kun-Ching Cho, ${ }^{6}$ and Xuan-Rong Lai ${ }^{1}$ \\ ${ }^{1}$ Graduate Institute of Manufacturing Technology, National Taipei University of Technology, Taipei 10608, Taiwan \\ ${ }^{2}$ Department of Vehicle Engineering, National Taipei University of Technology, Taipei 10608, Taiwan \\ ${ }^{3}$ Department of Industrial Design, National Taipei University of Technology, Taipei 10608, Taiwan \\ ${ }^{4}$ Graduate Institute of Mechanical and Electrical Engineering, National Taipei University of Technology, Taipei 10608, Taiwan \\ ${ }^{5}$ Department of Thoracic Surgery, Mackay Memorial Hospital, Taipei 10449, Taiwan \\ ${ }^{6}$ Department of Civil Engineering, Texas A \& M University, College Station, TX 77843-3136, USA
}

Correspondence should be addressed to Ho Chang; f10381@ntut.edu.tw

Received 8 March 2013; Accepted 21 May 2013

Academic Editor: Georgios Tzamalis

Copyright (C) 2013 Ho Chang et al. This is an open access article distributed under the Creative Commons Attribution License, which permits unrestricted use, distribution, and reproduction in any medium, provided the original work is properly cited.

This study used natural dyes as sensitizers of dye-sensitized solar cells (DSSCs) to replace expensive chemical synthetic dyes. We prepared two natural dyes, chlorophyll dye and anthocyanin dye, by extracting them from wormwood and purple cabbage, respectively. Moreover, we mixed the prepared chlorophyll dye and anthocyanin dye at 5 different volume ratios to form cocktail dyes. For preparation of photoelectrode, $\mathrm{P} 25 \mathrm{TiO}_{2}$ nanoparticles were used to prepare paste, which was coated on fluorine-doped tin oxide (FTO) conductive glass by the spin coating method at different spin coating speeds in order to form $\mathrm{TiO}_{2}$ thin films with different thicknesses. The DSSC prepared by the cocktail dye achieves photoelectric conversion efficiency $(\eta)$ of $1.95 \%$, open-circuit voltage $\left(V_{\mathrm{OC}}\right)$ of $0.765 \mathrm{~V}$, and short-circuit current density $\left(J_{\mathrm{SC}}\right)$ of $5.83 \mathrm{~mA} / \mathrm{cm}^{2}$. Moreover, the prepared DSSC sensitized solely by chlorophyll extract of wormwood achieved a photoelectric conversion efficiency $(\eta)$ of $0.9 \%$, whereas the DSSC sensitized solely by anthocyanin extract of purple cabbage achieved a photoelectric conversion efficiency of $1.47 \%$, achieving the longest lifetime of electrons amongst these three dyes.

\section{Introduction}

In 1954, Bell Laboratories introduced a crystalline silicon solar cell with efficiency reaching $4.5 \%$, bringing about the development of solar cells in the subsequent decades [1]. However, crystalline silicon solar cells have a disadvantage; that is, the process of making a single crystal silicon is very expensive. Therefore, the development of highly efficient and low-cost solar cells became a necessary trend. In the early 1990s, O’Regan and Grätzel developed the dye-sensitized solar cell (DSSC). This kind of solar cell can be prepared in a general environment, and the preparation cost is tremendously reduced [2]. On the other hand, compared to the crystalline silicon solar cell, DSSCs use a solid-liquid interface, which is produced from a solid-state semiconductor and an electrolyte as the driving force. Since the interface can be formed easily, the preparation process of DSSCs is simpler. Therefore, the photosensitive dye or $\mathrm{TiO}_{2}$ thin film electrode has aroused extensive study in academic circles. Many studies have investigated the application of nano- $\mathrm{TiO}_{2}$ made photoelectrode thin film to DSSCs.

In current studies of DSSCs, DSSCs are mostly sensitized by chemical synthetic dyes because their photoelectric conversion efficiency can reach 11-12\% [3, 4]. However, these kinds of synthetic dyes, such as N3 and N719, have high production costs and easily create environmental pollution. In comparison, fruits and vegetables are indispensable. Moreover, they are organic, easily obtainable, and inexpensive. Thus, fruits and vegetables can reduce the cost of DSSCs and achieve more economical and environmental protection effects. Since ruthenium dyes are very rare and expensive, there is considerable interest in recent times toward the use 
of natural organic dyes extracted from various plants, fruits, flowers, and leaves as molecular sensitizers in DSSCs [5]. Several natural pigments such as anthocyanin, chlorophyll, tannin, and carotene have been successfully used as sensitizers in DSSCs [6-11]. Hao et al. took extracts of black rice, capsicum, erythrina variegata flower, rosa xanthine, and kelp as natural dyes. His research results showed that the DSSC sensitized by black rice had the greatest photoelectric conversion efficiency at $0.327 \%$ [12]. Sirimanne et al. used anthocyanin in pomegranate as dye, and the photoelectric conversion efficiency of the prepared DSSC was $0.6 \%$ [13]. Calogero and Marco took the red Sicilian orange and purple eggplant as photosensitizers. The DSSC sensitized by red Sicilian orange achieved higher photoelectric conversion efficiency at $0.66 \%$ maximum [14]. Jin et al. took wormwood as a natural dye, and the photoelectric conversion efficiency of the prepared DSSC was $0.9 \%$ [15]. Calogero et al. used carrot and fruit of the overlord tree as natural dyes, and the photoelectric conversion efficiencies of the prepared DSSCs were $1.7 \%$ and $1.26 \%$, respectively [16]. Zhou et al. took 20 different kinds of natural dyes to conduct analysis and found that the DSSC prepared by mangosteen pericarp had the highest photoelectric conversion efficiency at 1.17\% [17]. Zhu et al. extracted a photosensitizer from frozen blackberries and purified single-wall nanotubes as the counterelectrodes to prepare a DSSC. The photoelectric efficiency of the prepared DSSC was $1.46 \%$ [18].

In DSSCs, dye plays an important role. It is better for a dye to possess wider light absorption features. Taking N3 and N719 as an example, they have an absorption band at a nearly full wavelength. However, most of the natural dyes have narrower light absorption wavelength ranges, so that the photoelectric conversion efficiency of the prepared DSSC cannot be increased. However, cocktail pigments make use of the light absorption complementary features of different pigments to increase the photoelectric conversion efficiency of DSSCs. Kumara extracted shisonin and chlorophyll from shiso leaves and then mixed them to form cocktail dye. The photoelectric conversion efficiencies of the prepared DSSC was as high as $1.3 \%$ [19]. Chang extracted chlorophyll from pomegranate and anthocyanin from mulberry, and the photoelectric conversion efficiency of the prepared DSSCs were $0.597 \%$ and $0.548 \%$, respectively. After mixing the extracted chlorophyll and anthocyanin in a volume ratio of $1: 1$, the photoelectric conversion efficiency of the prepared DSSC was increased to $0.722 \%$ [20]. This study extracted chlorophyll dye from wormwood and anthocyanin dye from purple cabbage and mixed the extracted chlorophyll dye and anthocyanin dye at 5 different ratios to blend a cocktail dye so as to increase the photoelectric conversion efficiency of DSSCs. As to the part of photoelectrode, we employed the spin coating method at three different speeds, 500, 1000, and $1500 \mathrm{rpm}$, to acquire photoelectrode thin films of three different thicknesses, and explored the effects of different thin film thicknesses on the photoelectric properties of the prepared DSSCs. Furthermore, this study also compared the effects of the DSSCs prepared by different natural dyes on voltage decay, lifetime of electrons, and incident photon to current efficiency (IPCE).

\section{Experimental Details}

The anthocyanin dye and chlorophyll dye used by this study were extracted from purple cabbage and wormwood, respectively. First of all, $40 \mathrm{~g}$ of purple cabbage was added to $80 \mathrm{~mL}$ of absolute ethanol. They were heated at $50^{\circ} \mathrm{C}$ by double-container boiling and stirred by a magnet for 30 minutes. Finally, impurities were filtered out by filter paper with pores at $0.1 \mu \mathrm{m}$, and then anthocyanin was prepared. Next, $2.632 \mathrm{~g}$ of wormwood was added to $50 \mathrm{~g}$ of absolute ethanol. The same extraction procedure was carried out again for anthocyanin, and then the chlorophyll dye was prepared. In addition, we prepared a cocktail dye by mixing the prepared anthocyanin dye and chlorophyll dye at five different volume ratios, $1: 1,1: 2,2: 1,1: 3$, and $3: 1$. As for the preparation procedure of $\mathrm{TiO}_{2}$ paste, $25 \mathrm{~g}$ of $\mathrm{P} 25 \mathrm{TiO}_{2}$ powder was added to $40 \mathrm{ml}$ of nitric acid solution at $0.1 \mathrm{M}$ and then added to $0.8 \mathrm{~g}$ of polyethylene glycol (PEG) $($ M.W. $=8000)$ and $2 \mathrm{ml}$ of Triton X-100. The blended solution was stirred well until all substances inside were completely dissolved. After that, the solution underwent ultrasonic oscillation for 2 hours, and $\mathrm{TiO}_{2}$ paste was prepared. For the process of making the photoelectrode, fluorine-doped tin oxide (FTO) conductive glass was firstly cut to the size of $2.5 \mathrm{~cm} * 2 \mathrm{~cm}$. The conductive glass was sequentially placed in acetone, deionized water, and ethyl alcohol and then underwent ultrasonic oscillation for 20 minutes. The washed and cleaned conductive glass was placed in an oven at $60^{\circ} \mathrm{C}$ to be baked dry. After the surface became dry, a $3 \mathrm{M}$ tape was stuck onto the conductive side of the conductive glass. Finally, spin coating was carried out at three preset spin coating speeds: 500,1000 , and $1500 \mathrm{rpm}$. The prepared paste was evenly coated on the conductive glass to prepare $\mathrm{TiO}_{2}$ thin films with three different thicknesses [21]. After that, having completed spin coating process, the conductive glass was placed at room temperature to be dried for 30 minutes. Then the conductive glass was placed in a sintering furnace to be heated with the temperature rising $10^{\circ} \mathrm{C} / \mathrm{min}$ until it reached $450^{\circ} \mathrm{C}$. After being heated continuously for one hour, the conductive glass was placed at room temperature again. Then the preparation of photoelectrode thin film was completed.

After the sintered $\mathrm{TiO}_{2}$ photoelectrode had been soaked in dye at a suitable temperature for 24 hours, the photoelectrode thin film could completely adsorb the dye molecules. This study blended $0.1 \mathrm{M}$ of LiI, $0.05 \mathrm{M}$ of $\mathrm{I}_{2}$, and $0.5 \mathrm{M}$ of 4-tert-butylpyridine and acetonitrile (ACN) to form an electrolyte. This study used tert-butylpyridine as an additive of electrolyte to increase the $V_{\text {oc }}$ value. However, the presence of pyridine derivative like TBP will decrease the $J_{\mathrm{sc}}$ value and result in a decrease in the overall efficiency of the prepared DSSC [22]. In order to solve this problem, this study used spin coating method at different spin speeds to acquire an even $\mathrm{TiO}_{2}$ thin film with optima thickness. A dropper was used to drop a certain amount of electrolyte on the counterelectrode, which was then covered by a photoelectrode. For the counterelectrode, a layer of platinum $(\mathrm{Pt})$ thin film with a thickness $20 \mathrm{~nm}$ was sputtered on fluorine-doped tin oxide (FTO) conductive glass, and sandwich assembling was finally 
conducted. The two sides were fixed by clamps, and simple packaging of DSSC was completed.

This study used a UV/visible spectrophotometer to measure the absorption spectra of different natural dyes so as to understand the feature peak positions and light absorption ranges of different dyes. The photoelectric conversion efficiencies were measured with a potentiostat under illumination by a Xe lamp as the light source and an I-V Curve Analyzer (Keithley 2400). The light intensity corresponding to AM 1.5 was calibrated using a standard silicon solar cell. The intensity of the light was $100 \mathrm{~mW} / \mathrm{cm}^{2}$. The measured results formed an $I-V$ curve. Through the $I-V$ curve, the open-circuit voltage $V_{\mathrm{OC}}(\mathrm{V})$, short-circuit current density $J_{\mathrm{SC}}\left(\mathrm{mA} / \mathrm{cm}^{2}\right)$, fill factor $(\mathrm{FF})$, lifetime of electrons, and open-circuit voltage decay can be acquired. Additionally, a Fourier transform infrared (FTIR) spectrophotometer was used to test the functional groups in the dye molecules. Field emission scanning electron microscopy (FE-SEM) was used to observe the surface and cross-section form of the $\mathrm{TiO}_{2}$ thin film. Furthermore, we used this measurement system to measure the incident photon to current efficiency (IPCE) of the prepared solar cell.

\section{Results and Discussion}

In the experiment, $\mathrm{P} 25 \mathrm{TiO}_{2}$ nanoparticles were used to prepare a paste. After using the spin coating method to coat the paste on FTO conductive glass, thermal treatment was carried out, and a layer of thin film was obtained. As shown in Figure 1, it can be observed from the FE-SEM image that the diameter of the $\mathrm{TiO}_{2}$ particle is around $25 \mathrm{~nm}$. It is also observed that there is no crack or gap on the thin film surface, and the particles are evenly distributed. After spin coating of $\mathrm{TiO}_{2}$ paste at 3 spin coating speeds, 500, 1000, and $1500 \mathrm{rpm}, 3$ thin films with 3 different thicknesses were prepared. Thin film thickness is related to spin coating speed and the viscosity of paste. The advantage of using the spin coating method is that the acquired thin film can achieve even thickness. As shown in the cross-section image of $\mathrm{TiO}_{2}$ thin film in Figures 2(a) 2(c), under the conditions of spin coating speeds at 500,1000 , and $1500 \mathrm{rpm}$, the thicknesses of 3 thin films are around 35, 24, and $18 \mu \mathrm{m}$, respectively.

Figure 3 shows the UV/visible absorption spectra of wormwood, purple cabbage, and cocktail dyes. As seen in the figure, these three dyes have better absorption features in the UV light zone. In the visible light zone, the absorption peaks of chlorophyll dye extracted from wormwood are at $410 \mathrm{~nm}$ and $660 \mathrm{~nm}$, and the main absorption ranges are $400-450 \mathrm{~nm}$ and $650-700 \mathrm{~nm}$. However, the absorption peak of anthocyanin dye extracted from purple cabbage is at $550 \mathrm{~nm}$, and the main absorption range is $450-650 \mathrm{~nm}$. It can be seen that within the range of $400-450 \mathrm{~nm}$, the light absorption abilities of chlorophyll, anthocyanin, and cocktail dyes appear to be decreasing. This study made use of the varied absorption features of chlorophyll and anthocyanin in the light visible zone and mixed chlorophyll dye with anthocyanin dye at a fixed volume ratio to form the cocktail dye. As seen in Figure 3, the cocktail dye also possesses the

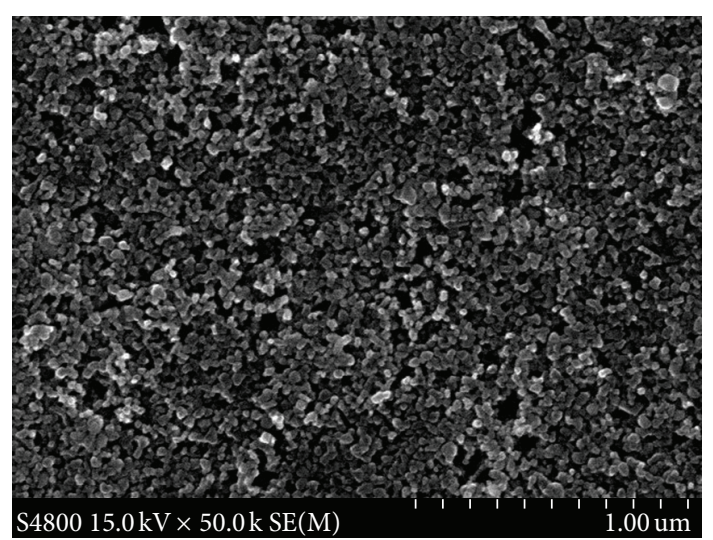

FIgURE 1: FE-SEM image of $\mathrm{TiO}_{2}$ thin film.

absorption peaks of both chlorophyll and anthocyanin and has an increased visible light absorption range, thus achieving the enhancement effect. Therefore, more electrons in excited state were transmitted to $\mathrm{TiO}_{2}$ to enhance the photocurrent strength of the solar cell.

The DSSC of this study took $\mathrm{TiO}_{2}$ thin film as photoelectrode thin film. Dyes need to have specific functional groups for them to be effectively adsorbed onto $\mathrm{TiO}_{2}$ thin film. As mentioned in a previous study [23], in the functional groups of chlorophyll dye and anthocyanin dye, esters, hydroxyl groups $(-\mathrm{OH})$, and carbonyl groups (-CO) bound with $\mathrm{TiO}_{2}$. Figure 4 shows the FTIR spectra of the spectral range within the wave band of $4000 \sim 400 \mathrm{~cm}^{-1}$. As observed from the functional groups of chlorophyll dye extracted from wormwood in Figure 4(a), $\mathrm{CH}_{3}$ vibration and $\mathrm{C}-\mathrm{H}_{2}$ vibration are observed at $2930 \mathrm{~cm}^{-1}$ and $2817 \mathrm{~cm}^{-1}$, respectively. Moreover, $\mathrm{C}=\mathrm{O}$ vibration at $1721 \mathrm{~cm}^{-1}, \mathrm{C}-\mathrm{O}$ vibration at $1045 \mathrm{~cm}^{-1}$, and $\mathrm{C}-\mathrm{N}$ vibration of porphyrins at $1644 \mathrm{~cm}^{-1}$ are also observed. As observed from the functional groups of anthocyanin dye extracted from purple cabbage in Figure 4(b), H-bond among molecules at $3418 \mathrm{~cm}^{-1}, \mathrm{C}=\mathrm{O}$ stretching vibration at $1639 \mathrm{~cm}^{-1}$, and stretching vibration of $\mathrm{C}-\mathrm{O}-\mathrm{C}$ esters at $1053 \mathrm{~cm}^{-1}$ are found.

This study mixed chlorophyll dye with anthocyanin dye to form a cocktail dye in order to achieve the complementary effect of light absorption. This act was advantageous to the photoelectric conversion efficiency of DSSC. As for the process of making the photoelectrode, the spin coating method was used to carry out spin coating at the spin coating speed of $500 \mathrm{rpm}$ for 5 seconds, and then a layer of $\mathrm{TiO}_{2}$ thin film with a thickness $35 \mu \mathrm{m}$ was prepared. As known from the experimental results shown in Table 1 and Figure 5, the DSSC sensitized by chlorophyll dye can achieve a photoelectric conversion efficiency of $0.538 \%$; the DSSC sensitized by anthocyanin dye can achieve a photoelectric conversion efficiency of $0.75 \%$. After chlorophyll dye and anthocyanin dye were mixed at a volume ratio of $1: 1$ to form the cocktail dye, it can be seen in the figure that the DSSC sensitized by the cocktail dye has the best photoelectric conversion efficiency at $1.29 \%$, short-current density at $3.16 \mathrm{~mA} / \mathrm{cm}^{2}$, and opencircuit voltage at $0.66 \mathrm{~V}$. Therefore, it can be proved that using 


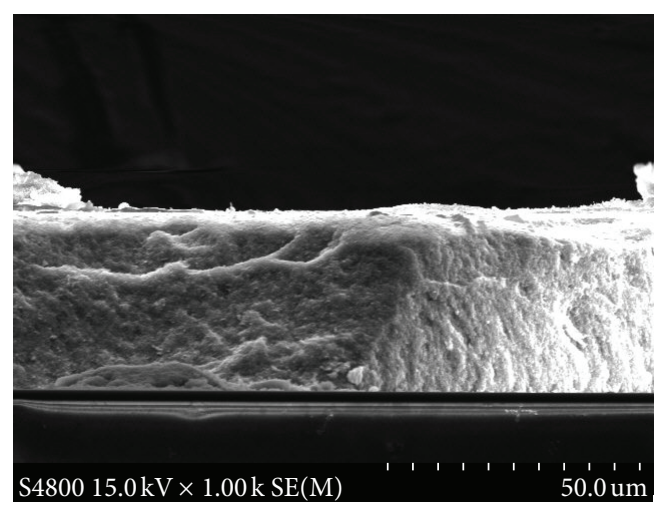

(a)

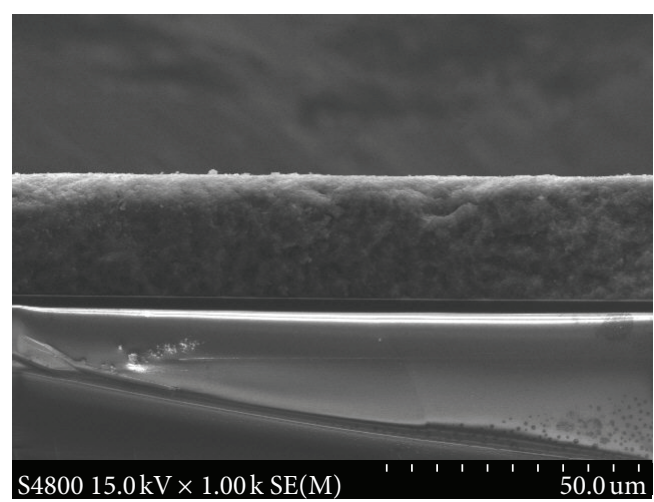

(b)

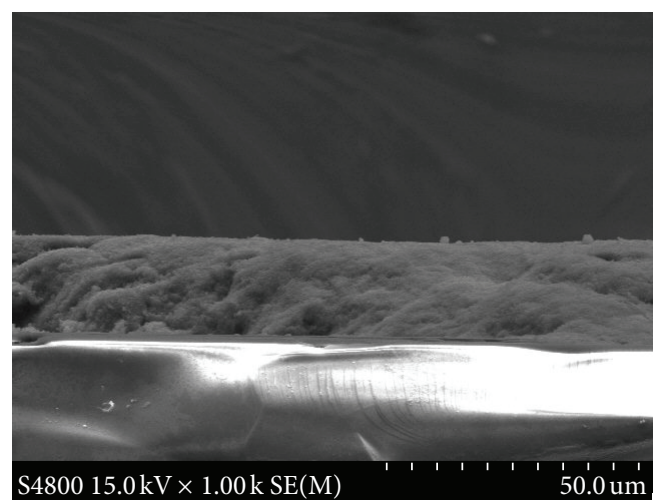

(c)

Figure 2: FE-SEM image of thin film thicknesses at (a) $35.66 \mu \mathrm{m}$, (b) $24.40 \mu \mathrm{m}$, and (c) $18.58 \mu \mathrm{m}$.

TABLE 1: Photoelectrical parameters of DSSCs sensitized by chlorophyll, anthocyanin, and cocktail dye.

\begin{tabular}{lcccc}
\hline Dye & $V_{\mathrm{oc}}(\mathrm{V})$ & $J_{\mathrm{sc}}\left(\mathrm{mA} / \mathrm{cm}^{2}\right)$ & $\mathrm{FF}(\%)$ & $\eta(\%)$ \\
\hline Wormwood & 0.585 & 1.96 & 47 & 0.538 \\
Purple cabbage & 0.66 & 2.08 & 53 & 0.75 \\
Cocktail dye & 0.66 & 3.16 & 62 & 1.29 \\
\hline
\end{tabular}

a cocktail dye as the sensitizer of a solar cell can enhance the performance of pure chlorophyll dye or pure anthocyanin dye.

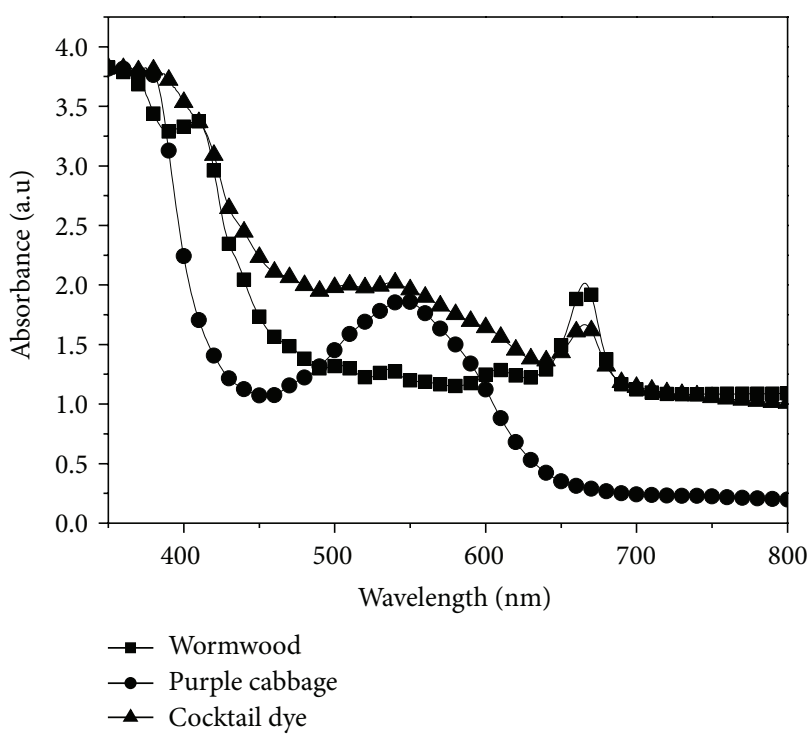

FIgURE 3: Absorption spectra of chlorophyll dye, anthocyanin dye, and cocktail dye.

TABLE 2: Photoelectrical parameters of DSSCs sensitized by cocktail dyes at different volume ratios.

\begin{tabular}{lcccc}
\hline $\begin{array}{l}\text { Wormwood: } \\
\text { Purple cabbage }\end{array}$ & $V_{\mathrm{oc}}(\mathrm{V})$ & $J_{\mathrm{sc}}\left(\mathrm{mA} / \mathrm{cm}^{2}\right)$ & $\mathrm{FF}(\%)$ & $\eta(\%)$ \\
\hline$(1: 1)$ & 0.66 & 3.16 & 62 & 1.29 \\
$(2: 1)$ & 0.675 & 2.55 & 67 & 1.15 \\
$(1: 2)$ & 0.635 & 1.98 & 52 & 0.652 \\
$(3: 1)$ & 0.605 & 2.82 & 53 & 0.896 \\
$(1: 3)$ & 0.585 & 2.01 & 52 & 0.612 \\
\hline
\end{tabular}

This study not only blended a cocktail dye at a volume ratio of $1: 1$ but also additionally blended 4 cocktail dyes at 4 different ratios. As for the process of making the photoelectrode, the spin coating method was used to carry out spin coating at a speed of $500 \mathrm{rpm}$ for 5 seconds, and then a layer of $\mathrm{TiO}_{2}$ thin film with a thickness of $35 \mu \mathrm{m}$ was prepared. As known from the experimental results shown in Figure 6 and Table 2, the prepared DSSC sensitized by the cocktail dye mixing two dyes at a ratio of $1: 1$ can achieve better photoelectric conversion efficiency at $1.29 \%$. However, for the DSSCs prepared by cocktail dyes mixed in ratios of $2: 1$ and $1: 2$, the photoelectric conversion efficiencies obviously fall to $1.15 \%$ and $0.652 \%$, respectively. Moreover, for the DSSCs prepared by cocktail dyes mixed at ratios of $3: 1$ and $1: 3$, the photoelectric conversion efficiencies are also poor, at only $0.896 \%$ and $0.615 \%$, respectively. Therefore, for the mixing ratio of the cocktail dyes, the DSSC sensitized by a cocktail dye with chlorophyll and anthocyanin dyes mixed at a ratio of $1: 1$ can achieve better photoelectric conversion efficiency. The reason for this was that the cocktail dye mixed at volume ratio of 1:1 had better light absorption and had less absorption competition and interference between dyes. As a result, better photoelectric conversion efficiency was obtained. 


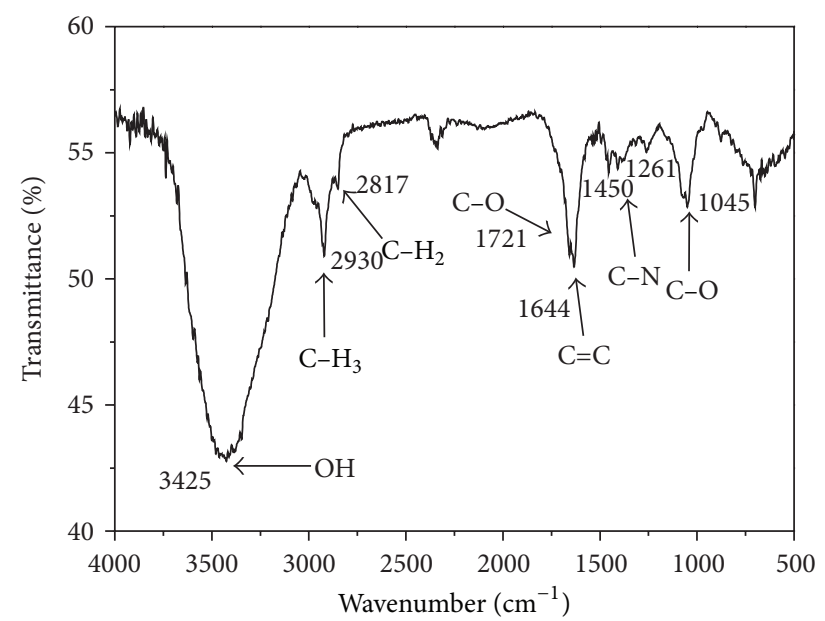

(a)

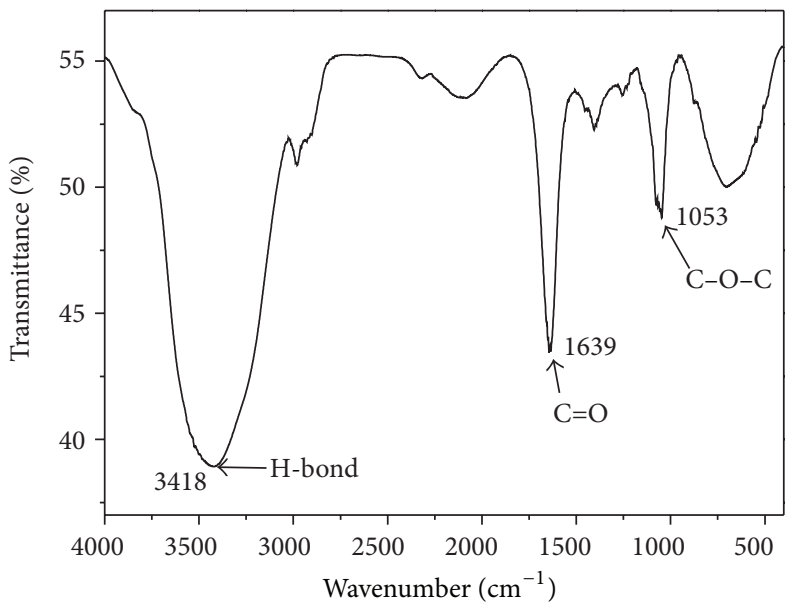

(b)

FIGURE 4: FTIR spectra of (a) chlorophyll dye, (b) anthocyanin dye.

TABLE 3: Photoelectrical parameters of DSSCs sensitized by cocktail dyes with different thicknesses of $\mathrm{TiO}_{2}$.

\begin{tabular}{lccccc}
\hline $\begin{array}{l}\text { Rotational } \\
\text { speed }(\mathrm{rpm})\end{array}$ & $\begin{array}{c}\text { Thickness } \\
(\mathrm{nm})\end{array}$ & $V_{\mathrm{oc}}(\mathrm{V})$ & $\begin{array}{c}J_{\mathrm{sc}} \\
\left(\mathrm{mA} / \mathrm{cm}^{2}\right)\end{array}$ & $\mathrm{FF}(\%)$ & $\eta(\%)$ \\
\hline 500 & 35.66 & 0.66 & 3.16 & 62 & 1.29 \\
1000 & 24.40 & 0.765 & 5.83 & 48 & 1.95 \\
1500 & 18.58 & 0.675 & 4.6 & 51 & 1.58 \\
\hline
\end{tabular}

Figure 7 shows the photoelectric conversion efficiency of DSSCs prepared with three different thin film thicknesses. As shown in the results in Figure 7 and Table 3, when the photoelectrode thin film thickness is $24.40 \mu \mathrm{m}$, the DSSC prepared has the best photoelectric conversion efficiency at $1.95 \%$. However for the DSSC prepared by a photoelectrode with a thin film thickness at $35.66 \mu \mathrm{m}$, the photoelectric conversion efficiency falls to $1.29 \%$. The reason is that, with the increase of photoelectrode thin film thickness, incident light could not effectively penetrate the bottom most layer of the thin film, restricting the transmission of the excited dye molecules to the photoelectrode. Furthermore, with a photoelectrode thin film thickness of $18.58 \mu \mathrm{m}$, the photoelectric conversion efficiency of the DSSC falls slightly to $1.58 \%$. The reason is that, with the gradual decrease of photoelectrode thin film thickness, the amount of dye adsorption on $\mathrm{TiO}_{2}$ thin film was decreased, so that its photoelectric conversion efficiency was relatively low. As proved in the experiments, under the condition where the photoelectrode thin film thickness is at $24.40 \mu \mathrm{m}$, the photoelectric conversion efficiency of the DSSC sensitized by chlorophyll dye reached $0.9 \%$, and the photoelectric conversion efficiency of the DSSC sensitized by anthocyanin dye reached $1.47 \%$.

Figure 8 shows the voltage decay feature of the DSSCs sensitized by the three natural dyes. This experimental test was conducted for 60 seconds. After DSSCs were continuously irradiated by light for 5 seconds, the light was turned off. As seen in the results shown in Figure 8, under illuminating

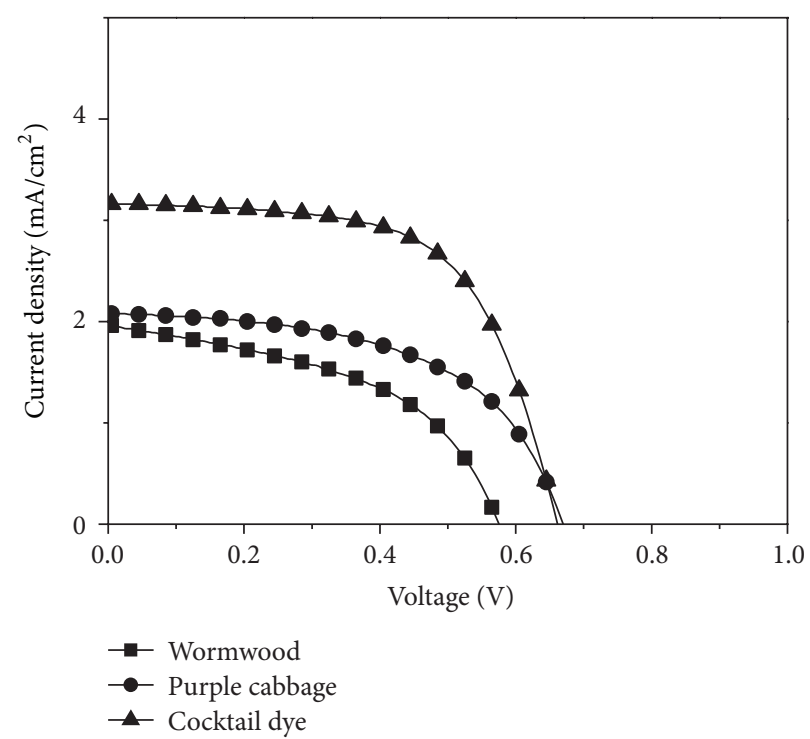

FIGURE 5: $J-V$ curve of DSSCs sensitized by chlorophyll, anthocyanin, and cocktail dye.

condition, the $V_{\mathrm{oc}}$ of these 3 dyes appears to be at constant values. After the light was removed, the voltage decay time of the anthocyanin dye was the longest. After 60 seconds, it still had around $0.1 V_{\text {oc }}$. The voltage value of chlorophyll dye fell rapidly to zero after 20 seconds, but the voltage value of the cocktail dye was the only one close to zero after 30 seconds. After conversion of the results acquired in Figure 8 by the equation, the lifetime of electrons can be acquired, as shown in Figure 9. As seen in Figure 9, the DSSC sensitized by anthocyanin dye had longer lifetime of electrons. In contrast, the DSSC sensitized by chlorophyll dye had the shortest lifetime of electrons. The reason was that when the light was turned off, the extent of electrolyte oxidization of the chlorophyll dye molecules in the excited state was stronger, and the electrons in the $\mathrm{TiO}_{2}$ thin film could be easily 


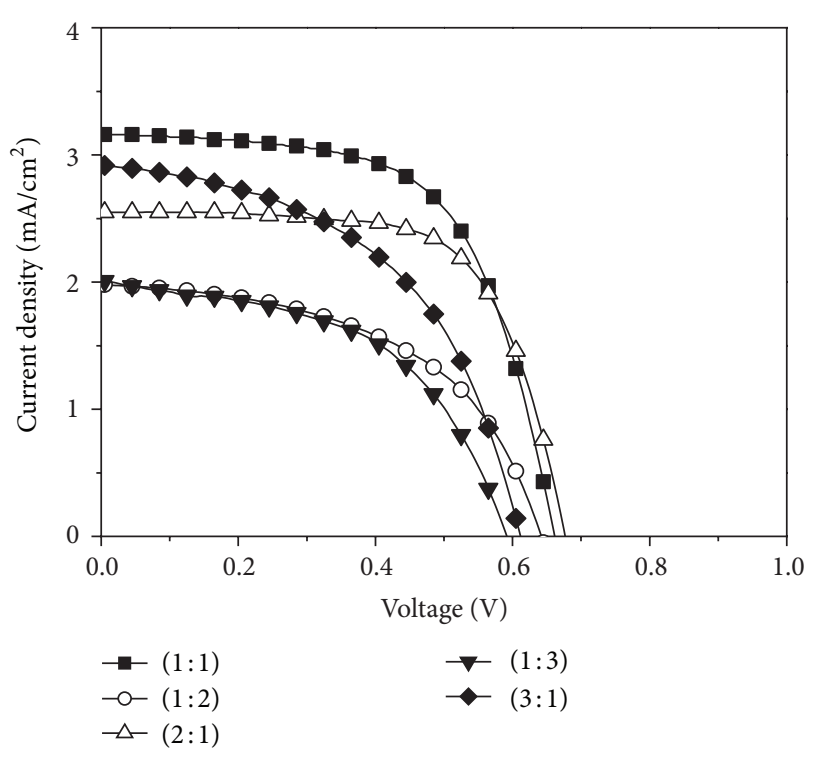

FIGURE 6: $J$-V curves of DSSCs sensitized by cocktail dyes at different volume ratios.

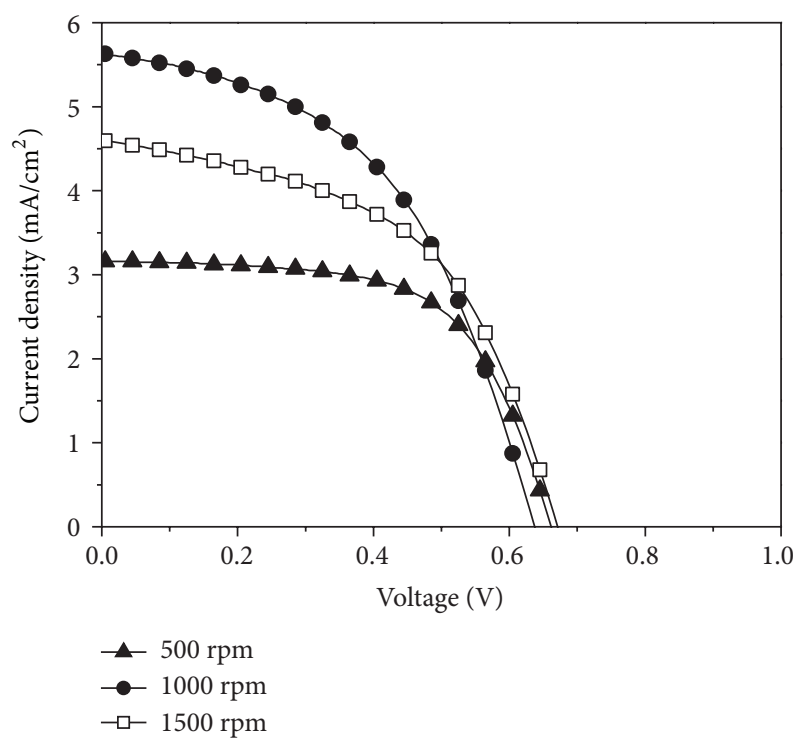

Figure 7: $J-V$ curves of DSSCs sensitized by cocktail dyes with different thicknesses of $\mathrm{TiO}_{2}$.

captured by $\mathrm{I}_{3}$ ions in the electrolyte. Therefore, the lifetime of electrons of the DSSC with chlorophyll dye was relatively short.

For the raw pigment extracts prepared by the paper and yielding higher quantum and energy conversion efficiencies, the mechanisms involved are (1) dye has functions of broadening the spectral response due to presence of many chromophore molecules and forestering type energy transfer between different chromophore molecules. Besides, pigment molecules contain radical group that can easily combine with the surface of nanosemiconductor. For example, $-\mathrm{COOH}$ or $-\mathrm{CO}$ on pigment would combine with $-\mathrm{OH}$ on $\mathrm{TiO}_{2}$ to form esters, thus increasing the electronic coupling of $3 \mathrm{~d}$

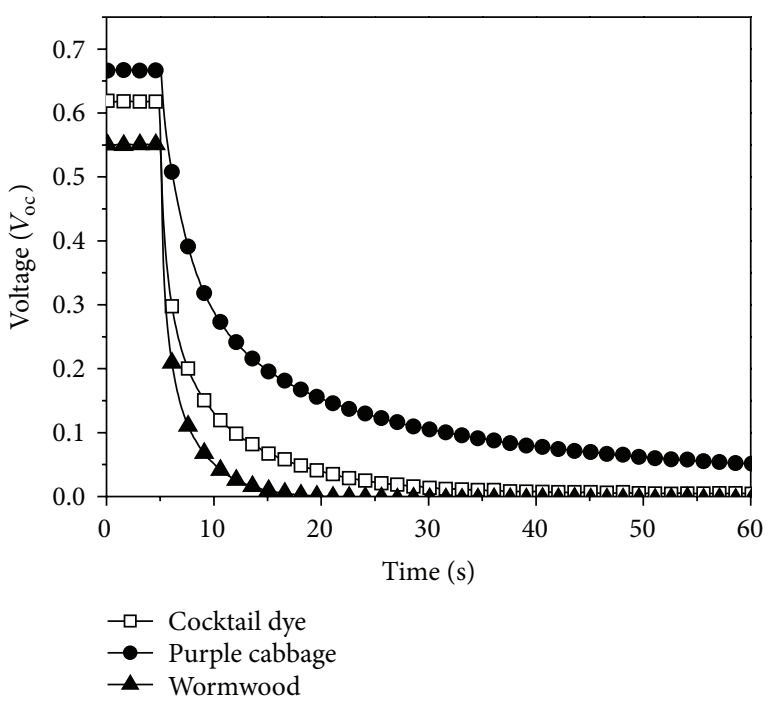

FIGURE 8: Open-circuit voltage decay of DSSCs sensitized by chlorophyll, anthocyanin, and cocktail dye.

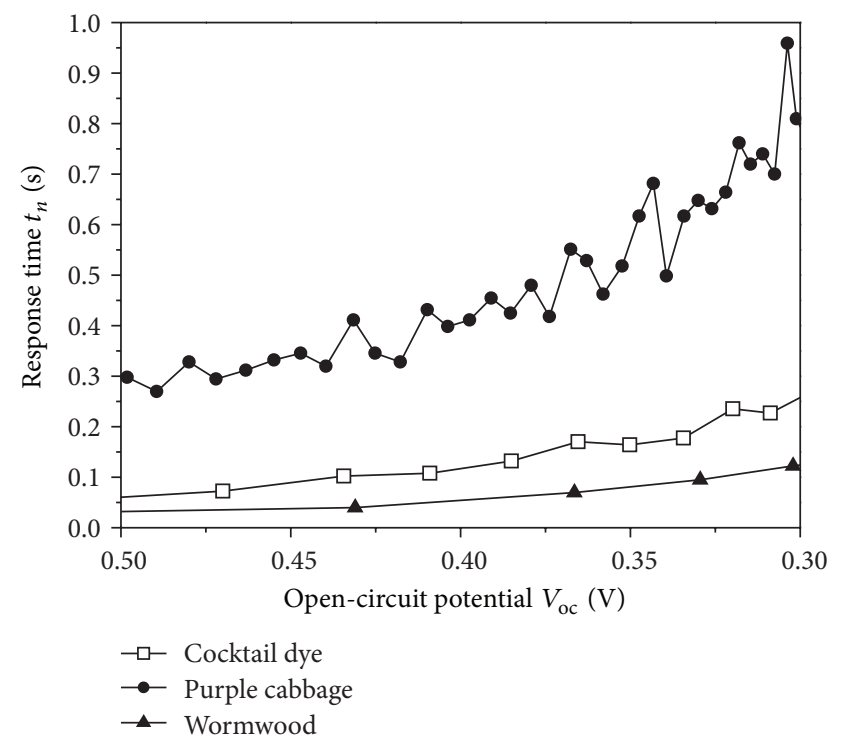

FIGURE 9: Lifetime of electrons of DSSCs sensitized by chlorophyll, anthocyanin, and cocktail dye.

orbital of $\mathrm{TiO}_{2}$ conduction band and $\pi$ orbital of pigment and making electronic transition easier. In addition, suppression of concentration quenching is due to presence of effective nonchromophore molecules. (2) The oxidation state $\left(D^{*}\right)$ and excited state $\left(D^{*}\right)$ of dye has higher stability and activity, and the life of dye in excited state has longer life and higher electric charge transmission efficiency. Besides, pigment has sufficient oxidation-reduction potential in excited state in order to ensure that the excited electrons can inject on $\mathrm{TiO}_{2}$ conduction band. In addition, relatively low potential energy exists in oxidation-reduction process (ground state and excited state) so as to suffer less loss of free energy in the process of first and secondary electron transfer. 


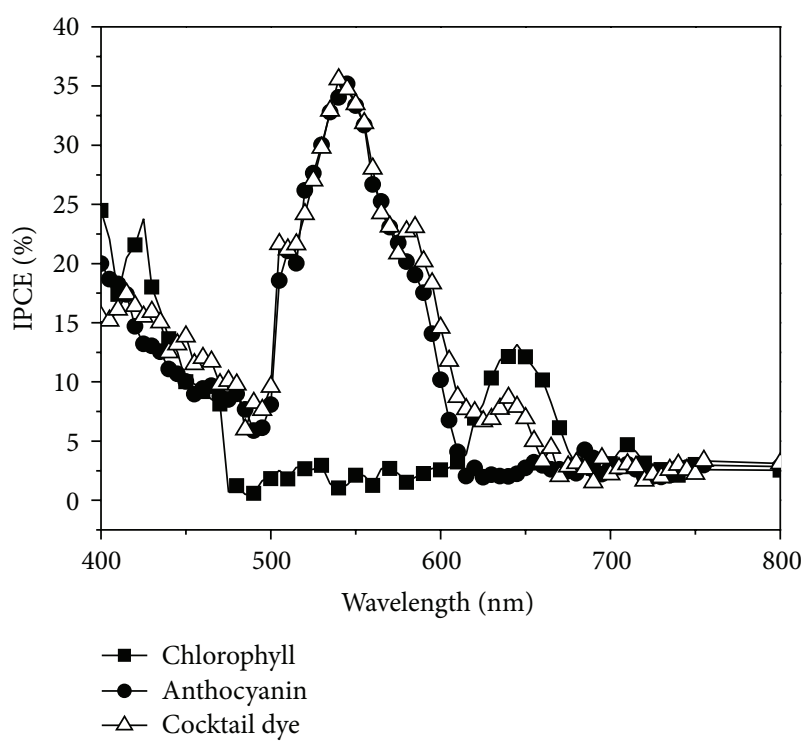

FIGURE 10: IPCE curves of DSSCs sensitized by chlorophyll, anthocyanin, and cocktail dye.

Figure 10 shows the IPCE of the prepared DSSCs sensitized by chlorophyll, anthocyanin, and cocktail dye. As shown in the figure, when the incident light wavelength is at $420 \mathrm{~nm}$, the DSSC prepared by chlorophyll dye has the greatest IPCE value at around 24\%; when the incident light wavelength is at $550 \mathrm{~nm}$, the DSSC prepared by anthocyanin dye has the greatest IPCE value at around 37\%. After chlorophyll and anthocyanin dyes were mixed to form cocktail dye, it can be seen in the figure that, within the wavelength range of $510-580 \mathrm{~nm}$ in the light visible zone, the situation is similar to that of anthocyanin dye in that they have higher IPCE values. Therefore, within the light visible range, the DSSC sensitized by the cocktail dye has better ability to transform light energy into electricity energy than do the other two DSSCs. Moreover, comparing the UV-VIS curve with the IPCE curve, it can be proved that the cocktail dye has similar absorption features in relation to the visible light range and IPCE.

\section{Conclusions}

This study used natural dyes as sensitizers for DSSCs. We extracted chlorophyll and anthocyanin from wormwood and purple cabbage, respectively, to serve as natural dyes. Additionally, this study mixed chlorophyll dye and anthocyanin dye at different volume ratios to form cocktail dyes. As known from the experimental results shown in the UV/VIS and IPCE curves, the cocktail dye possesses light absorption range and IPCE features of both dyes. Moreover, the DSSC sensitized by cocktail dye significantly enhanced the photoelectric conversion efficiencies of the two single dyes before mixing, $0.538 \%$ and $0.75 \%$, to $1.29 \%$ after mixing. In addition, as shown in the experimental result of the effects of different $\mathrm{TiO}_{2}$ thin film thicknesses on photoelectric conversion efficiency, the DSSC prepared with a photoelectrode thin film thickness at around $24 \mu \mathrm{m}$ has the highest photoelectric conversion efficiency of $1.95 \%$.

\section{Acknowledgment}

This study was supported by the National Science Council of Taiwan, Taiwan, under Project Grant no. NSC 100-2221E-027-012.

\section{References}

[1] D. M. Chapin, C. S. Fuller, and G. L. Pearson, "A new silicon $p-n$ junction photocell for converting solar radiation into electrical power," Journal of Applied Physics, vol. 25, no. 5, pp. 676-677, 1954.

[2] B. O'Regan and M. Grätzel, "A low-cost, high-efficiency solar cell based on dye-sensitized colloidal $\mathrm{TiO}_{2}$ films," Nature, vol. 353, no. 6346, pp. 737-740, 1991.

[3] Y. Chiba, A. Islam, Y. Watanabe, R. Komiya, N. Koide, and L. Y. Han, "Dye-sensitized solar cells with conversion efficiency of 11.1\%," Japanese Journal of Applied Physics, vol. 45, no. 24-28, pp. L638-L640, 2006.

[4] R. Buscaino, C. Baiocchi, C. Barolo et al., "A mass spectrometric analysis of sensitizer solution used for dye-sensitized solar cell," Inorganica Chimica Acta, vol. 361, no. 3, pp. 798-805, 2008.

[5] V. Shanmugama, S. Manoharanb, S. Anandanb, and R. Murugan, "Performance of dye-sensitized solar cells fabricated with extracts from fruits of ivy gourd and flowers of red frangipani as sensitizers," Spectrochimica Acta A, vol. 104, pp. 35-40, 2013.

[6] N. J. Cherepy, G. P. Smestad, M. Grätzel, and J. Z. Zhang, "Ultrafast electron injection: implications for a photoelectrochemical cell utilizing an anthocyanin dye-sensitized $\mathrm{TiO}_{2}$ nanocrystalline electrode," Journal of Physical Chemistry B, vol. 101, no. 45, pp. 9342-9351, 1997.

[7] A. S. Polo and N. Y. Murakami Iha, "Blue sensitizers for solar cells: natural dyes from Calafate and Jaboticaba," Solar Energy Materials and Solar Cells, vol. 90, no. 13, pp. 1936-1944, 2006.

[8] A. Kay and M. Grätzel, "Artificial photosynthesis. 1. Photosensitization of $\mathrm{TiO}_{2}$ solar cells with chlorophyll derivatives and related natural porphyrins," Journal of Physical Chemistry, vol. 97, no. 23, pp. 6272-6277, 1993.

[9] G. R. A. Kumara, S. Kaneko, M. Okuya, B. Onwona-Agyeman, A. Konno, and K. Tennakone, "Shiso leaf pigments for dyesensitized solid-state solar cell," Solar Energy Materials and Solar Cells, vol. 90, no. 9, pp. 1220-1226, 2006.

[10] R. Espinosa, I. Zumeta, J. L. Santana et al., "Nanocrystalline $\mathrm{TiO}_{2}$ photosensitized with natural polymers with enhanced efficiency from 400 to $600 \mathrm{~nm}$," Solar Energy Materials and Solar Cells, vol. 85, no. 3, pp. 359-369, 2005.

[11] N. M. Gómez-Ortíz, I. A. Vázquez-Maldonado, A. R. PérezEspadas, G. J. Mena-Rejón, J. A. Azamar-Barrios, and G. Oskam, "Dye-sensitized solar cells with natural dyes extracted from achiote seeds," Solar Energy Materials and Solar Cells, vol. 94, no. 1, pp. 40-44, 2010.

[12] S. C. Hao, J. H. Wu, Y. F. Huang, and J. M. Lin, "Natural dyes as photosensitizers for dye-sensitized solar cell," Solar Energy, vol. 80, no. 2, pp. 209-214, 2006.

[13] P. M. Sirimanne, M. K. I. Senevirathna, E. V. A. Premalal, and P. K. D. D. P. Pitigala, "Enhancement of the photoproperties of solid-state $\mathrm{TiO}_{2}$ /dye/CuI cells by coupling of two dyes," 
Semiconductor Science and Technology, vol. 21, no. 6, pp. 818821, 2006.

[14] G. Calogero and G. D. Marco, "Red Sicilian orange and purple eggplant fruits as natural sensitizers for dye-sensitized solar cells," Solar Energy Materials and Solar Cells, vol. 92, no. 11, pp. 1341-1346, 2008.

[15] E. M. Jin, K. H. Park, B. Jin, J. J. Yun, and H. B. Gu, "Photosensitization of nanoporous $\mathrm{TiO}_{2}$ films with natural dye," Physica Scripta, vol. 2010, Article ID 014006, 2010.

[16] G. Calogero, G. D. Marco, S. Cazzanti et al., "Efficient dyesensitized solar cells using red turnip and purple wild Sicilian prickly pear fruits," International Journal of Molecular Sciences, vol. 11, no. 1, pp. 254-267, 2010.

[17] H. Zhou, L. Wu, Y. Gao, and T. Ma, "Dye-sensitized solar cells using 20 natural dyes as sensitizers," Journal of Photochemistry and Photobiology A, vol. 219, no. 2-3, pp. 188-194, 2011.

[18] H. Zhu, H. Zeng, V. Subramanian, C. Masarapu, K.-H. Hung, and B. Wei, "Anthocyanin-sensitized solar cells using carbon nanotube films as counter electrodes," Nanotechnology, vol. 19, no. 46, Article ID 465204, 2008.

[19] G. R. A. Kumara, S. Kaneko, M. Okuya, B. Onwona-Agyeman, A. Konno, and K. Tennakone, "Shiso leaf pigments for dyesensitized solid-state solar cell," Solar Energy Materials and Solar Cells, vol. 90, no. 9, pp. 1220-1226, 2006.

[20] H. Chang and Y. J. Lo, "Pomegranate leaves and mulberry fruit as natural sensitizers for dye-sensitized solar cells," Solar Energy, vol. 84, no. 10, pp. 1833-1837, 2010.

[21] S. V. Nitta, A. Jain, P. C. Wayner et al., "Effect of sol rheology on the uniformity of spin-on silica xerogel films," Journal of Applied Physics, vol. 86, no. 10, pp. 5870-5878, 1999.

[22] G. Calogero, J. H. Yum, A. Sinopoli, G. Di Marco, M. Grätzel, and M. K. Nazeeruddin, "Anthocyanins and betalains as lightharvesting pigments for dye-sensitized solar cells," Solar Energy, vol. 86, no. 5, pp. 1563-1575, 2012.

[23] M. A. Riyaz Ahmad and N. Nafarizal, "Study on $\mathrm{TiO}_{2}$ film for dye-sensitized solar cell using natural dyes," in Proceedings of the International Conference on Enabling Science and Nanotechnology (ESciNano '10), pp. 1-2, December 2010. 

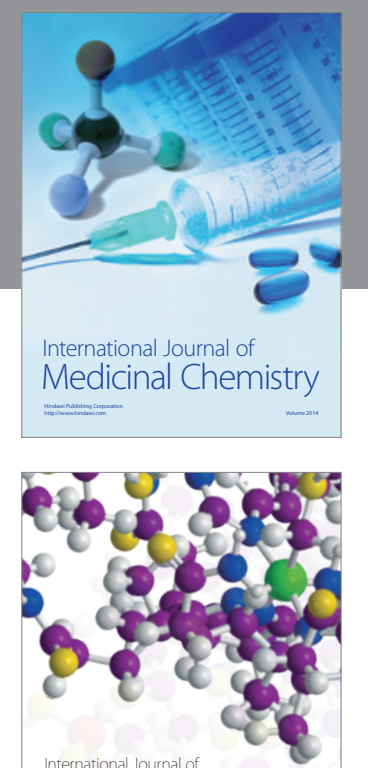

\section{Carbohydrate} Chemistry

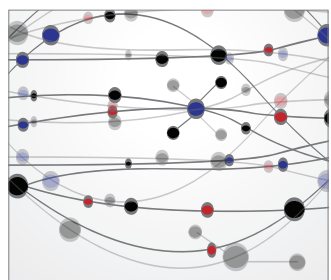

The Scientific World Journal
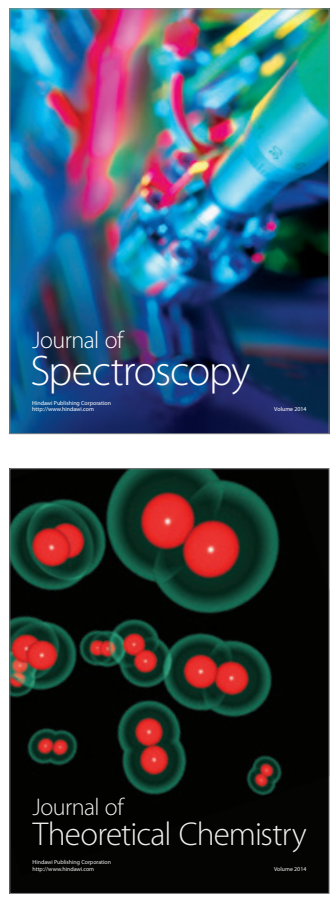
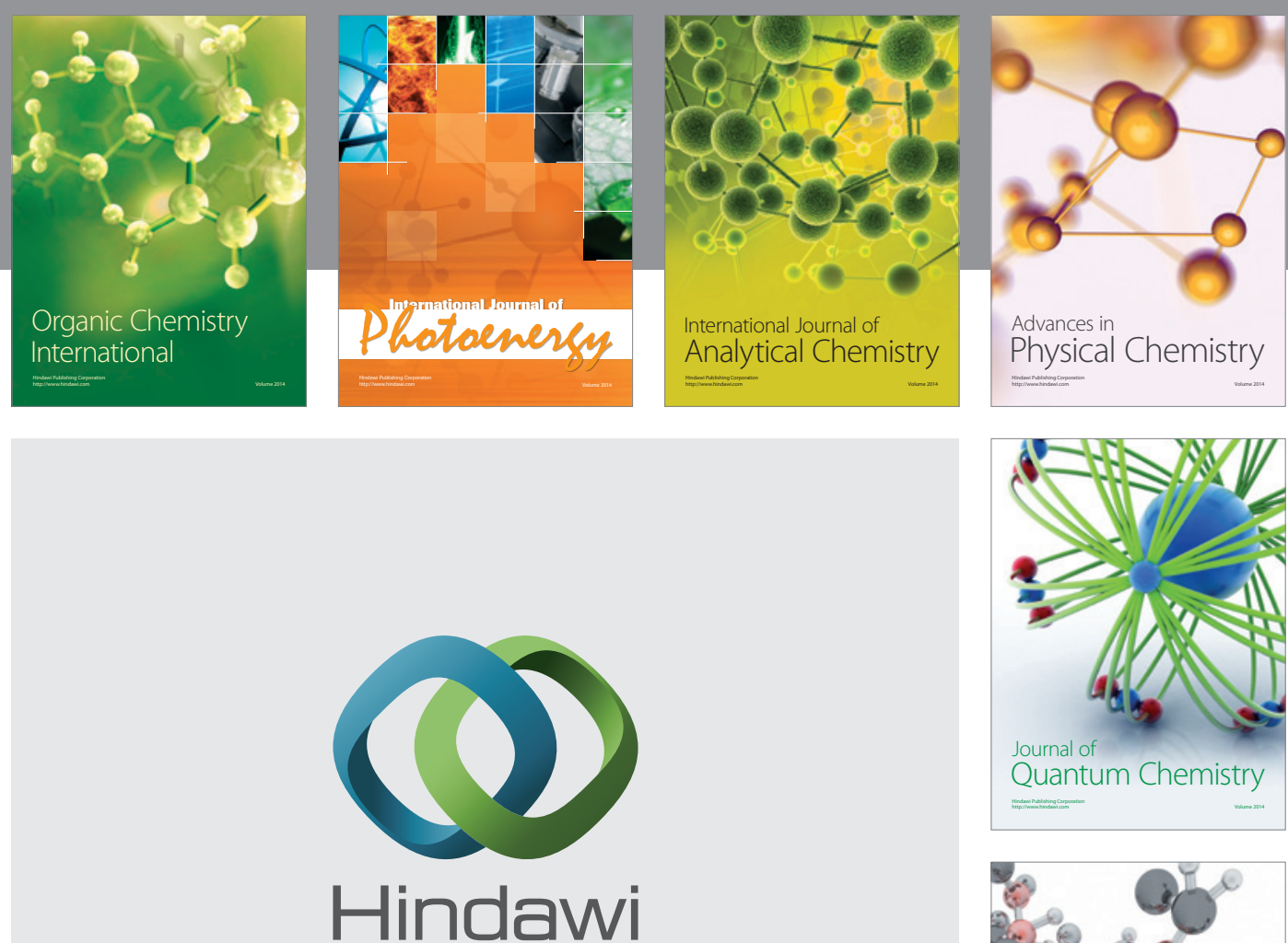

Submit your manuscripts at

http://www.hindawi.com

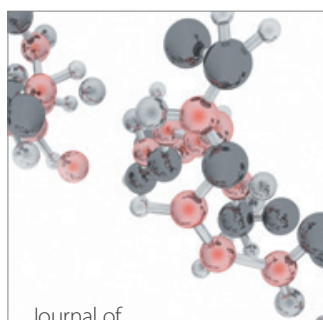

Analytical Methods

in Chemistry

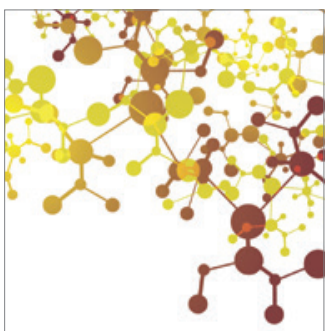

Journal of

Applied Chemistry

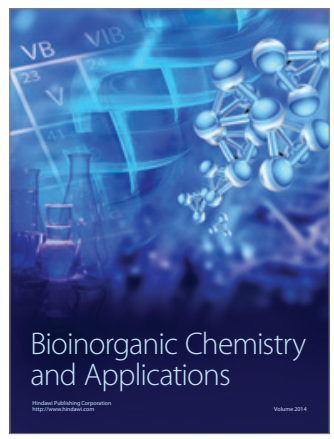

Inorganic Chemistry
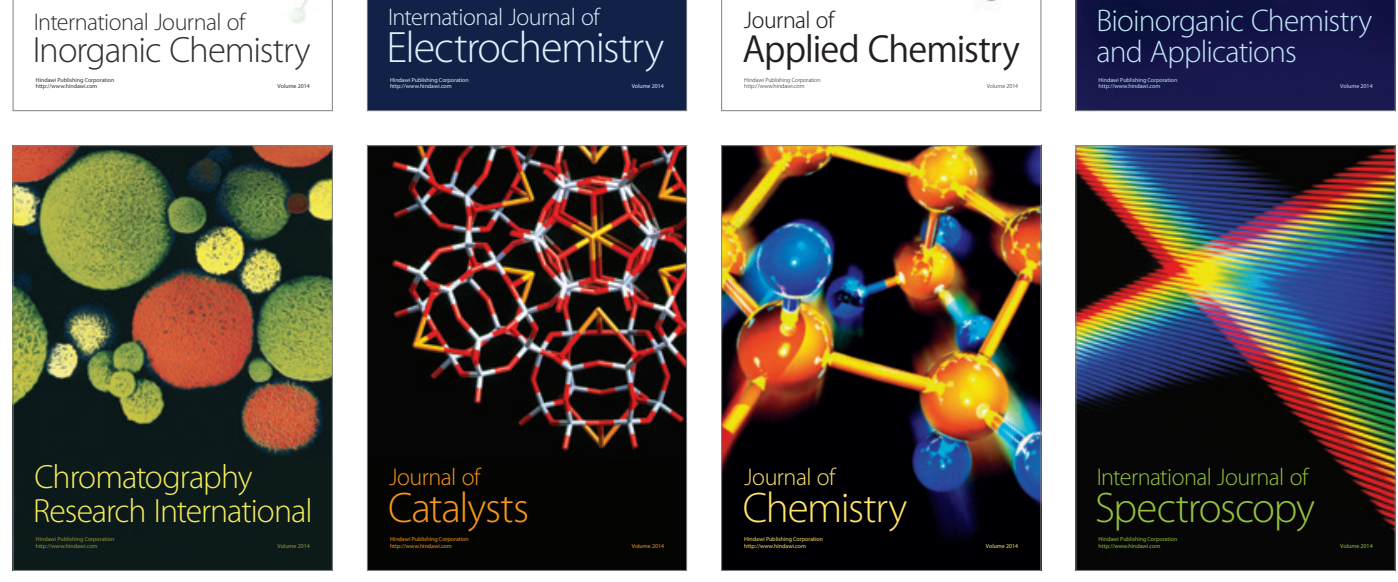